\title{
Evaluation of Metal-loaded Activated Carbon Electrode for Electrochemical Capacitor Prepared by Plasma CVD Method
}

\author{
Keiichi OKAJIMA, ${ }^{*}$ Naotake SAKUMOTO, Takashi ToYA, and Masao SUDOH
}

Department of Materials Science and Chemical Engineering, Faculty of Engineering, Shizuoka University (3-5-1 Johoku, Hamamatsu 432-8561, Japan)

Received December 4, 2000 ; Accepted March 1, 2001

\begin{abstract}
Aiming to increase the capacitance with double-layer capacitance and pseudocapacitance, metal-loaded active carbon fiber (ACF) electrodes for use in electrochemical capacitors were prepared by the plasma enhanced chemical vapor deposition method. Platinum was used as the loaded material, and the preparation conditions such as substrate temperature, concentration of the aqueous Pt solution and plasma output were investigated. For the Pt-loaded ACF samples with a specific surface area of $1,500 \mathrm{~m}^{2} / \mathrm{g}$, the capacitance increased by $24 \%$ compared to the untreated sample, and the highest electric capacity value of $306 \mathrm{~F} / \mathrm{g}$ was achieved at a substrate temperature of the $250^{\circ} \mathrm{C}$.
\end{abstract}

Key Words : Electrochemical Capacitor, Active Carbon Fiber, Plasma CVD, Metal-loaded Electrode

\section{Introduction}

Electrochemical capacitors have recently become of major interest as energy storage systems because of their higher power density than those of dielectric capacitors, and have a longer cycle life than batteries. ${ }^{1,2}$ The electric double layer capacitor using the activated carbon electrode is one of the main developmental research areas in this field. An activated carbon fiber ${ }^{3-5}$ ) and an activated carbon powder ${ }^{6,7)}$ are popular materials for the electrode of the electric double layer capacitor because of their high specific surface area and high conductivity. However, there seems to be a limit to the double layer capacity only by increasing the specific surface area of the activated carbon. On the other hand, the capacitors based on a faradic process due to redox reactions are called pseudocapacitors. These electrodes are formed with a noble metal or transition metal oxide such as $\mathrm{Pt}, \mathrm{RuO}_{2}, \mathrm{IrO}_{2}, \mathrm{NiO}_{x}$, and have the advantages of high specific capacitance and high conductivity. ${ }^{8-10)}$ However, proton diffusion is a relatively slower process so that the power of such faradic devices is limited. It would be advantageous to disperse nano-size particles of a metal or metal oxide on a double layer support with a high surface area such as an activated carbon. The composite electrode fabricated by the Sol-Gel method has been reported. ${ }^{11,12)}$

In this study, aiming to increase the capacitance with double-layer capacitance and pseudocapacitance, metalloaded active carbon fiber (ACF) electrodes for the electrochemical capacitor were prepared by the plasma enhanced chemical vapor deposition (plasma CVD) method. The formation of nano-size fine particles can be expected using the plasma CVD process. In this study, platinum was used as the loaded material, and the preparation conditions such as substrate temperature, concentration of the aqueous Pt solution and plasma output were investigated.

\section{Experimental}

An ACF cloth was used as the support and its specific surface area was $1,500 \mathrm{~m}^{2} / \mathrm{g}$ (Toyobo, KF-1500F). Figure 1 shows a schematic diagram of the apparatus used for the RF-plasma enhanced chemical vapor deposition treatment (Samco BP-1). The plasma CVD system is the conventional planar capacitive type consisting of a reaction chamber, a gas feeding system, a pumping system and a RF-power supply. $\mathrm{H}_{2} \mathrm{PtCl}_{6}$ was used as the reactant and introduced with $\mathrm{H}_{2}$ gas as the reducing agent into the reaction chamber. $\mathrm{H}_{2} \mathrm{PtCl}_{6}$ and $\mathrm{H}_{2}$ passed through the inside of the RF-electrode, and then these reactive species were uniformly sprayed from the RF-electrode located above the ACF cloth. The $\mathrm{H}_{2} \mathrm{PtCl}_{6}$ container was kept at room temperature and the $\mathrm{H}_{2} \mathrm{PtCl}_{6}$ flow rate was controlled by changing the concentration of the $\mathrm{H}_{2} \mathrm{PtCl}_{6}$ aqueous solution. The standard $\mathrm{H}_{2}$ flow rate was $10 \mathrm{~cm}^{3}$ $\min ^{-1}$ and the $\mathrm{H}_{2} / \mathrm{Ar}$ flow ratio was $20 \%$. The pressure in the reactor was set at $67 \mathrm{~Pa}$ and an RF Power of $5 \mathrm{~W}$ to $10 \mathrm{~W}$ was supplied to generate the plasma. The substrate was heated with a conventional coil heater in the reaction chamber and its temperature was controlled in

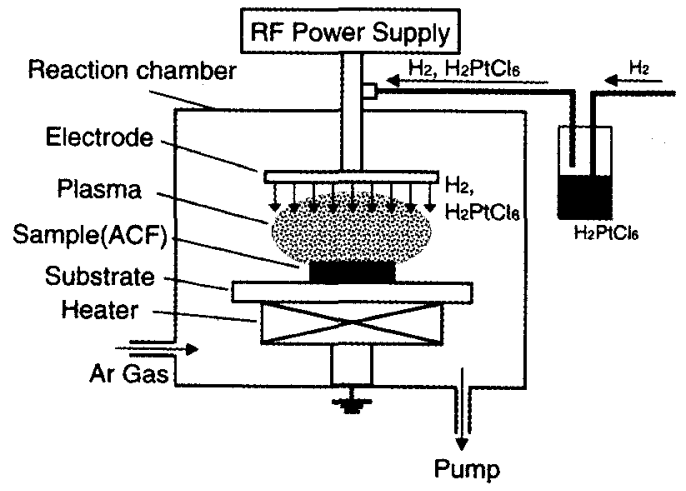

Fig. 1 Schematic diagram of the plasma CVD apparatus. 
the range to $450^{\circ} \mathrm{C}$. Each electrode was exposed to the plasma for $1 \mathrm{~min}$. Pt contents were estimated from the measured dry weight of RF-CVD treated samples. The crystallinity of the Pt particles was investigated using an X-ray diffractometer (Rigaku, RINT-2000) with $\mathrm{CuK} \alpha$ radiation. The morphology of loaded Pt particles was observed using scannning electron microscopy (JEOL JSM5600, JSM-6401F).

For the electrochemical measurements using cyclic voltammetry, a two-electrode coin-type shaped cell was used. The ACF and Pt-loaded ACF electrodes were all 16 $\mathrm{mm}$ in diameter. The measurements were carried out at room temperature using a potentiostat (Hokuto Denko $\mathrm{HZ}-3000)$. A glass filter was used as the separator. As the electrolyte solution, $0.5 \mathrm{~mol} / l \mathrm{H}_{2} \mathrm{SO}_{4}$ was used for all of the measurements and the electrochemical treatments. The typical sweep rate was $5 \mathrm{mVs}^{-1}$ and the number of cycles was 5 for the cyclic voltammetry in order to determine the capacitance.

\section{Results and Discussion}

Figure 2 shows a SEM image of a Pt-loaded ACF electrode prepared at a substrate temperature of $150^{\circ} \mathrm{C}$, with a $0.064 \mathrm{~mol} / l$ concentration of $\mathrm{H}_{2} \mathrm{PtCl}_{6}$ solution and a 10 $\mathrm{W}$ of RF-power. From this result, the formation of particles $20 \mathrm{~nm}$ or less was confirmed, though the particle size was about $150 \mathrm{~nm}$ for the sample prepared by impregnation. ${ }^{13)}$ Besides, particles were also formed in the macroscopic hole and the grain size was about $50 \mathrm{~nm}$. Based on the SEM observation of the cross sectional direction, the $\mathrm{Pt}$ particles were uniformly formed on the carbon fibers. This indicated that CVD deposition was taken place even inside the ACF felt. In the XRD measurement, the peak corresponding to Pt was confirmed, while the peaks of Pt-oxide or Pt-chloride were not observed.

Figure 3 shows the result of the cyclic voltammetry for the electrode formed at $350^{\circ} \mathrm{C}$. Each curve had almost an ideal rectangular shape. The CV curve for the Pt-loaded electrodes is similar to those for the $\mathrm{RuO}_{2}$ electrode ${ }^{14)}$ and the $\mathrm{RuO}_{2}$-carbon composite electrode, ${ }^{15}$ ) and was mainly featureless between the hydrogen and oxygen evolutions. This result indicates that the charge exchanged between the $\mathrm{Pt}$ and the electrolyte at a constant rate. ${ }^{14)}$

The effect of substrate temperature during RF-CVD treatment on the capacitance is shown in Fig. 4. For the case of the $\mathrm{H}_{2} \mathrm{PtCl}_{6}$ solution concentration of $0.064 \mathrm{~mol} / l$, the capacitance increased with increasing substrate temperature, and the capacitance became a maximum at $350^{\circ} \mathrm{C}$. Pt contents also increased with rising substrate temperature. Maximum values of the $\mathrm{Pt}$ content were $7.3 \%$ and $10.3 \%$ by weight with plasma outputs of $5 \mathrm{~W}$ and $10 \mathrm{~W}$, respectively. Both values were obtained at the same substrate temperature of $350^{\circ} \mathrm{C}$. This suggested that the capacitance improved by increasing the quantity of Pt particles. However, the Pt particles were agglomerated at the substrate temperature of $450^{\circ} \mathrm{C}$ from the SEM results. Therefore, it was considered that the specific surface area of the Pt particle decreased and the agglomer-

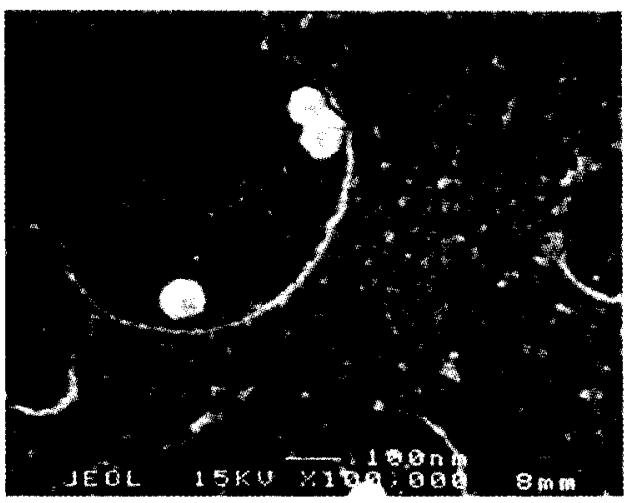

Fig. 2 SEM image of the Pt-loaded ACF surface.

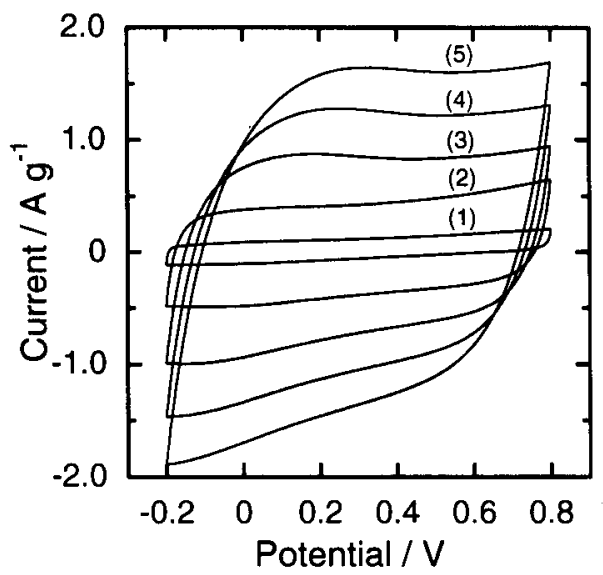

Fig. 3 Cyclic voltammogram of the Pt-loaded ACF electrode with a substrate temperature of $350^{\circ} \mathrm{C}$ during CVD treatment. Sweep rate: 1)1, 2)5, 3)10, 4)15, 5) $20 \mathrm{mV} \mathrm{s}^{-1}$.

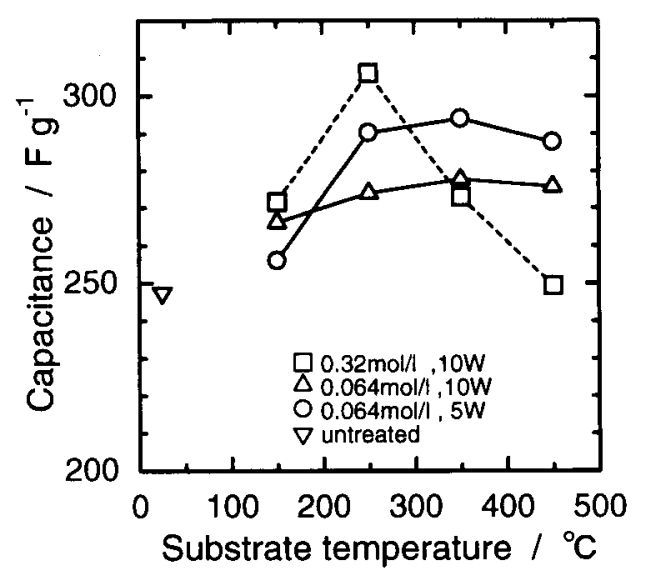

Fig. 4 The specific capacitance as a function of the substrate temperature during CVD treatment for Pt-loaded ACF electrodes.

ated grain plugged the pores of the ACF. For the solution concentration of $0.32 \mathrm{~mol} / l$ and plasma output of 10 $\mathrm{W}$, the highest electric capacity value of $306 \mathrm{~F} / \mathrm{g}$ was achieved for the substrate temperature of $250^{\circ} \mathrm{C}$. This result corresponded to an increase of $24 \%$ over that of the untreated electrode. This was different from the result at the low concentration $(0.064 \mathrm{~mol} / l)$, where the electrode capacitance drastically decreased at the substrate temperature above $350^{\circ} \mathrm{C}$. It seemed that the capacity de- 


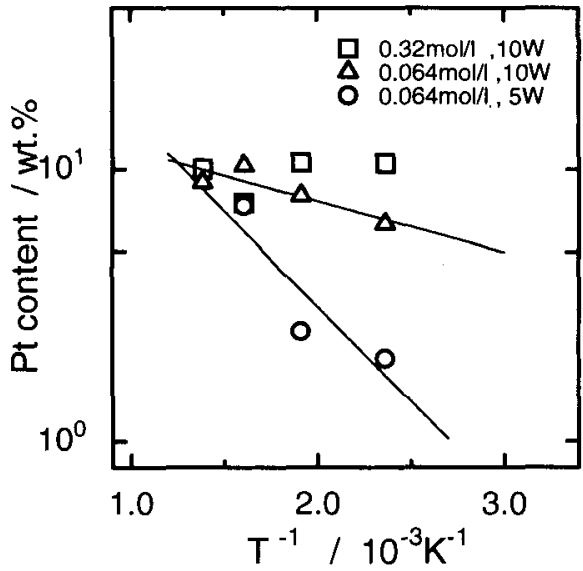

Fig. 5 Dependence of the deposition temperature on the $\mathrm{Pt}$ content ratio.

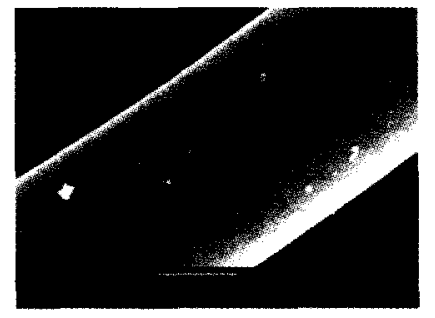

(a)

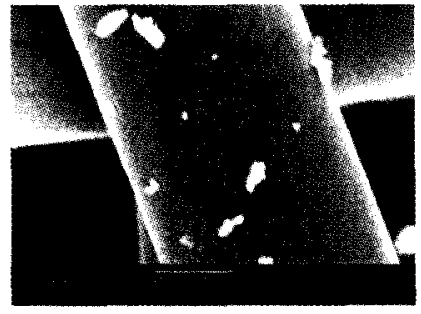

(b)
Fig. 6 SEM images of Pt-loaded ACF electrodes prepared at $250^{\circ} \mathrm{C}$ (a), $450^{\circ} \mathrm{C}$ (b), with a $\mathrm{H}_{2} \mathrm{PtCl}_{6}$ concentration of $0.32 \mathrm{~mol}$ $/ l$.

creased with a relatively high concentration of $\mathrm{H}_{2} \mathrm{PtCl}_{6}$ solution because the agglomeration of the Pt particle was promoted at the lower temperature.

The Arrhenius-type plot of the relation between the substrate temperature and the Pt content is shown in Fig. 5. In the low solution concentration of $\mathrm{H}_{2} \mathrm{PtCl}_{6}(0.064 \mathrm{~mol}$ $/ l)$, the Pt content increased for plasma outputs of $5 \mathrm{~W}$ and $10 \mathrm{~W}$ with an increase in the substrate temperature, and a linear relation was found. For the plasma outputs of $5 \mathrm{~W}$ and $10 \mathrm{~W}$, the apparent activation energies for the Pt deposition assuming an Arrhenius-type equation were $194 \mathrm{~J} / \mathrm{mol}$ and $52 \mathrm{~J} / \mathrm{mol}$, respectively. The effect of a thermal assist was higher with the plasma output of $5 \mathrm{~W}$ as was expected, and the increment of the electrode capacitance increased with rising substrate temperature compared to the plasma output of $10 \mathrm{~W}$ (Fig. 4). On the other hand, there was no correlation with the substrate temperature and the Pt content for the high solution concentration of $\mathrm{H}_{2} \mathrm{PtCl}_{6}(0.32 \mathrm{~mol} / l)$, and the Pt content did not agree with the change in the electrode capacitance (Fig. 4). Especially, there was quite a difference for the electrode capacitance between the electrode prepared at $250^{\circ} \mathrm{C}$ and that at $450^{\circ} \mathrm{C}$ substrate temperatures during CVD treatment in spite of the Pt content of about $10 \%$ for both electrodes. SEM images of these electrodes are shown in Fig. 6a and Fig. 6b, respectively. It was confirmed that large Pt particles agglomerated and formed grains of about $1 \mu \mathrm{m}$ or larger at the substrate temperature of $450^{\circ} \mathrm{C}$ (Fig. 6b). In addition, no Pt particle of 20 nm or less was observed on the ACF surface and it was considered that large grains were formed with small particles by surface diffusion. This agglomeration decreased the specific surface area of the Pt particle, therefore the capacitance became lower than that of prepared at the substrate temperature of $250^{\circ} \mathrm{C}$ (Fig. 6a).

\section{Conclusion}

Pt-loaded ACF electrodes for use in electrochemical capacitors were prepared by the plasma enhanced chemical vapor deposition method, and the electrode capacitance was improved by the contribution of the Pt pseudocapacitance. Pt particles of $20 \mathrm{~nm}$ or less were formed by using the plasma CVD technique. In addition, Pt particle formation in the macroscopic holes was confirmed. For the Pt-loaded ACF electrodes with a specific surface area of $1,500 \mathrm{~m}^{2} / \mathrm{g}$, the capacitance increased by $24 \% \mathrm{com}-$ pared with the untreated sample, and the highest value of the electric capacity of $306 \mathrm{~F} / \mathrm{g}$ was achieved with the sample prepared at the $250^{\circ} \mathrm{C}$ substrate temperature. At a low concentration of reactive species, an Arrhenius-type plot for the relationship between the substrate temperature and the Pt content became linear, and the electrode capacitance increased with the increase in the Pt content. However, the electrode capacitance decreased even with the equivalent $\mathrm{Pt}$ content by agglomeration of the $\mathrm{Pt}$ particles for the sample having high content of reactive species.

\section{References}

1) J. P. Zheng, J. Huang, and T. R. Jow, J. Electrochem. Soc., 144, 2026 (1997).

2) T. Momma, S. Komaba, and T. Osaka, Denki Kagaku (presently Electrochemistry), 65, 115 (1997).

3) I. Tanahashi, A. Yoshida, and A. Nishino, J. Electrochem. Soc., 137, 3052 (1990).

4) S. Iwasaki, Y. Okusako, M. Miyahara, and M. Okazaki, Kagaku Kougaku Ronbunshu, 23, 512 (1997).

5) M. Ishikawa, A. Sakamoto, M. Morita, and Y. Matsuda, $J$. Power Sources, 60, 233 (1996).

6) M. Takeuchi, K. Koike, T. Mauyama, A. Mogami, and M. Okamura, Denki Kagaku (presently Electrochemistry), 66, 1311 (1998).

7) Y. Kibi, T. Saito, M. Kuata, J. Tabuchi, and A. Ochi, $J$. Power Sources, 60, 219 (1996).

8) Y. Takasu, T. Nakamura, H. Ohkawauchi, and Y. Murakami, J. Electrochem. Soc., 144, 2601 (1997).

9) J. P. Zheng, P. J. Cygan, and T. R. Jow, J. Electrochem. Soc., 142, 2699 (1995).

10) K. C. Liu and M. A. Anderson, J. Electrochem. Soc., 144, 2026 (1996).

11) J. M. Miller, B. Dunn, T. D. Tran, and R. W. Pekala, J. Electrochem. Soc., 144, L 309 (1997).

12) Y. Sato, K. Yomogida, T. Nanaumi, K. Kobayakawa, Y. Ohsawa, and M. Kawai, Electrochem. Solid-State Lett., 3 , $113(2000)$.

13) T. Toya, K. Okajima, and M. Sudoh, 33rd Autumn Meeting of the Society of Chemical Engineers, Japan, Abstr., p.X304 (2000) (in Japanese).

14) J. P. Zheng and T. R. Jow, J. Electrochem. Soc., 142, L6 (1995).

15) J. P. Zheng, Electrochem. Solid-State Lett., 2, 359 (1999). 